\title{
Erratum
}

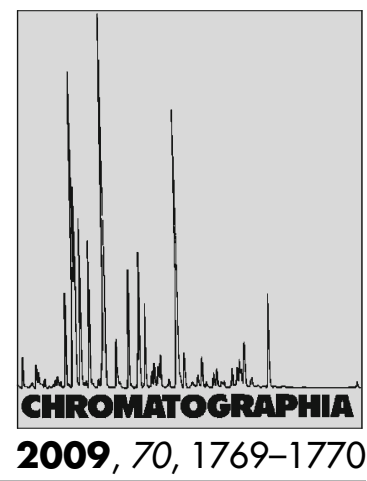

\section{Erratum to: Simultaneous Determination of Benzodiazepines and Ketamine from Alcoholic and Nonalcoholic Beverages by GC-MS in Drug Facilitated Crimes}

Munevver Acikkol ${ }^{\bowtie}$, Selda Mercan, Sukriye Karadayi

Institute of Forensic Sciences, Istanbul University, 34303 Istanbul, Turkey; E-Mail: acikkolm@istanbul.edu.tr; ackolm@yahoo.com

\section{Erratum to: Chromatographia (2009) 70:1 295-1298}

DOI 10.1365/s10337-009-1278-6

Unfortunately, in the original article the assignments of the chromatograms a, b, c and d in Fig. 1 was confused. The correct assignment is as follows: 

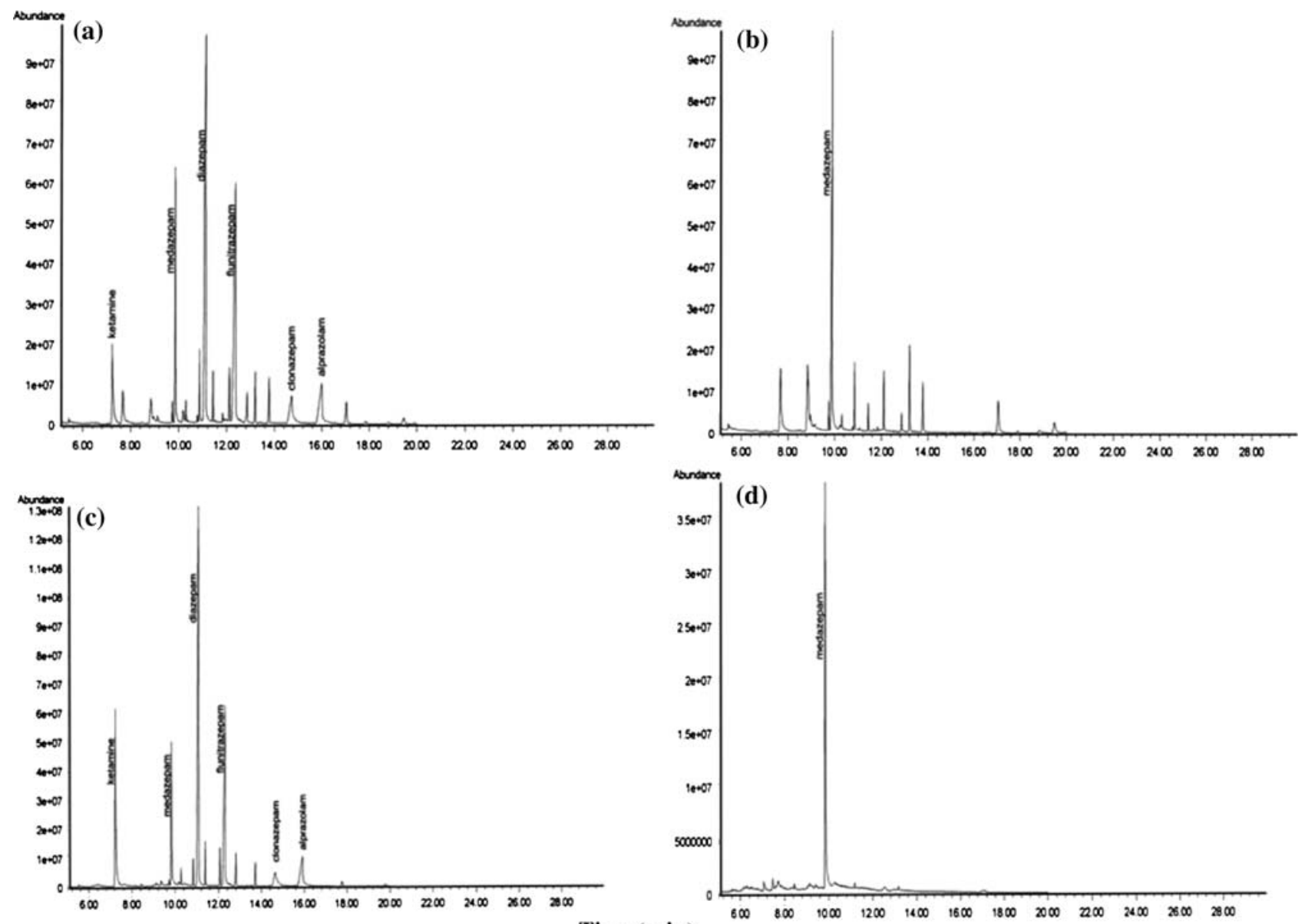

Time (min)

Fig. 1. The chromatograms of drug mixture in peach juice (a), blank peach juice (b), drug mixture in beer (c), and blank beer (d) 